\title{
PENILAIAN PRESTASI MAKLUM BALAS 360 DARJAH DARI PERSPEKTIF ISLAM: SATU TINJAUAN
}

\section{THE 360 DEGREE FEEDBACK APPROACH FROM THE ISLAMIC PERSPECTIVE: AN ANALYSIS}

\author{
AB. AZIZ YUSOF \\ School of Business Management \\ Universiti Utara Malaysia
}

\begin{abstract}
Abstrak
Penilaian prestasi merupakan nadi kepada kehidupan organisasi serta fungsi penting dalam pengurusan sumber manusia. Pelaksanaannya sering diselubungi oleh pelbagai masalah psikososial yang menyebabkan berlakunya konflik, ketidakpuasan, kebimbangan, tekanan, ketandusan upaya dan lainlain. Tanggapan ketidakadilan dalam pelaksanaan dan pengaruh politik pejabat merupakan punca utama kepada permasalahan ini. Bagi berhadapan dengan masalah ini, pelbagai kaedah penilaian prestasi telah diperkenalkan antaranya ialah Maklum Balas 360 Darjah. Walau bagaimanapun, didapati pelaksanaan kaedah ini juga masih lagi terdedah kepada pelbagai kelemahan yang berpunca daripada kesilapan manusia (human errors). Menyedari permasalahan yang dihadapi, kertas kerja ini cuba meneroka pendekatan penilaian prestasi Maklum Balas 360 Darjah daripada perspektif Islam sebagai gantian kepada kaedah konvensional. Kertas kerja ini akan membincangkan justifikasi keperluan kepada pendekatan Islam, pelakupelaku yang terlibat dalam pelaksanaannya serta ciri-ciri yang perlu ada pada pendekatan penilaian prestasi Maklum Balas 360 Darjah daripada perspektif Islam.
\end{abstract}

Kata kunci: Penilaian prestasi, penilaian prestasi Maklum Balas 360 Darjah, penilaian prestasi Maklum Balas 360 Darjah dari perspektif Islam.

\begin{abstract}
Purpose - The purpose of this paper is to discuss the flaw in implementing performance appraisal that raises a number of psycological problems as a result of injustice and political influence during its implementation. To overcome these problems, a new method known as the 360 Degree Feedback
\end{abstract}


was introduced. However, it was found that the implementation of this method still has many weaknesses caused by human errors. In conjunction with the problem, this research seeks to explore the 360 Degree Feedback approach from the Islamic perspective as a substitute for the conventional method. This paper will discuss the justification of using the Islamic approach, the subjects involved in the implementation, and the necessary features of the 360 Degree Feedback from the Islamic perspective.

Design/Methodology/Approach - The study was a library-based research. Therefore, the data collected depended on an extensive review of the literature. The contents of the identified journals, articles and books were rigorously and carefully analysed to enable the conclusion to be made.

Originality/Value - The result of this research can be used as a platform for future researchers to explore it through empirical support. Hopefully, the performance appraisal 360 Degrees Feedback through the Islamic perspective can be a substitude to the traditional approach.

Keywords: performance appraisal, performance appraisal 360 degree feedback, performance appraisal 360 degree feedback from the Islamic perspective.

\section{Pengenalan}

Penilaian prestasi adalah fungsi penting lagi bermasalah dalam pengurusan sumber manusia (Baron \& Kreps, 1999; Ivancevich, 2001; Chen \& Kuo, 2004). Kajian-kajian terdahulu membuktikan pelbagai kaedah pelaksanaan berasaskan satu sumber telah menimbulkan pelbagai masalah psikososial antaranya menyebabkan ketidakpuasan kerja, konflik, kebimbangan, rasa tertekan dan ketandusan upaya. Situasi sebegini menyebabkan banyak pihak menerima penilaian prestasi sebagai fungsi yang menimbulkan pelbagai kesulitan (Ivancevich, 2001; Roberts, 1998; Derven, 1990; Taylor, Tracy, Renard, Harisson \& Carroll, 1995).

Bagi berhadapan dengan masalah ini, pendekatan penilaian prestasi yang datang dari pelbagai sumber telah diperkenalkan antaranya penilaian prestasi Maklum Balas 360 Darjah (Edwards \& Ewen, 1996). Thach (2002) melihat kaedah ini sebagai program pembangunan pengurusan yang paling cepat berkembang terutama dalam organisasi multinasional. Sungguhpun begitu, didapati pelaksanaannya turut diselubungi oleh pelbagai masalah terutama berpunca daripada kesilapan manusia (human errors) seperti berlaku pilih kasih (Comerford, 2002; Albright \& Carr, 1997), stereotaip 
(Robbins, 2005; Rudner, 1992) dan politik pejabat (Deondra, 2006; Zivnuska, Kacmar, Witt, Carlson, \& Bratton (2004). Akibatnya, banyak pihak mempersoalkan keberkesanan pelaksanaannya (Wimer, 2002). Rentetan daripada ini O'Reilly (1994) telah menyuarakan kebimbangannya apabila mendapati kaedah ini cukup menakutkan pihak yang dinilai (ratees). Hal ini kerana maklumat yang diperoleh bukan sahaja bersifat peribadi tetapi boleh menjejaskan reputasi pekerja yang dinilai. Bagi beliau adalah sukar untuk menerima kritikan sebagai sesuatu yang konstruktif apabila kebanyakan penilai menyatakan tugas pekerja yang dinilai adalah sangat tidak terurus sehingga boleh menjejaskan ketepatan pemarkahan yang sepatutnya diterima.

Menyedari tentang permasalahan ini, Moses, Hollenbeck dan Sorcher (1993) telah mengenal pasti lima kelemahan utama yang sering berlaku dalam pelaksanaan kaedah ini. Pertama, kaedah ini telah dikritik kerana terlalu bergantung kepada generalisasi umum ke atas ciri-ciri atau sifat-sifat individu pekerja yang dinilai. Kedua, terlalu bergantung kepada keterhadan atau tiada satu kerangka rujukan dalam membuat sesuatu pertimbangan (judgments). Ketiga, kaedah ini juga dikritik kerana bergantung kepada penerangan yang tidak lengkap. Keempat, terdapatnya kebimbangan terhadap kemampuan penilai untuk menterjemahkan gelagat dan pencapaian ke dalam bentuk angka pengkadaran. Dan yang terakhir, kaedah ini dilihat terlalu bergantung kepada sistem pembentukan pengkadaran untuk tujuan pentadbiran bukan untuk penentuan ganjaran.

Akibat daripada pelbagai masalah yang dihadapi telah membangkitkan rasa ketidakpuasan dalam kalangan pengurus dan pekerja terhadap pelaksanaannya (Dacri, 2005; Roberts, 1998; Edwards, 1989) kerana kesan akhirnya telah menyebabkan berlakunya pelbagai kesulitan (Latham \& Wexley, 1994). Menyedari permasalahan yang dihadapi mendorong pengkaji untuk membuat penerokaan terhadap kemampuan Islam sebagai gantian kepada pelaksanaannya. Bagi pengkaji, pendekatan Islam dalam mengemukakan jalan penyelesaian kepada permasalahan ini perlu diterokai setelah pelbagai pendekatan telah diambil tetapi terus terbukti menemui kebuntuan.

\section{Kenapa Perlu Pendekatan Islam dalam Pelaksanaan Penilaian Prestasi Maklum Balas 360 Darjah?}

Pendekatan Islam dalam pengurusan termasuk pelaksanaan penilaian prestasi Maklum Balas 360 darjah telah menimbulkan minat banyak 
pihak untuk mendalaminya. Bagi Kazmi dan Ahmad (2006) perkara ini didorong oleh peningkatan minat terutama dalam kalangan ahli akademik untuk melihat model pengurusan yang terkeluar daripada kerangka model pengurusan Amerika (American management models) seperti melihat model pengurusan dari perspektif keagamaan seperti Confucius, Hindu, Kristian dan Islam. Gesaan sebegini turut dikemukakan oleh Abbas, Gibbs dan Camp (2000) yang menjelaskan betapa perlunya ketiga-tiga ajaran agama wahyu iaitu Islam, Kristian dan Judaisme diambil kira dalam pengurusan organisasi telah membuktikan bahawa kepercayaan dan nilai-nilai agama mempunyai kesan yang signifikan ke atas tingkah laku pekerja termasuk aspek kepuasan kerja (King \& Williamson, 2005), gaya kepimpinan (Reave, 2005) dan persoalan berkaitan dengan etika (Weaver \& Agle, 2002).

Sementara itu, bagi Junaidah (2009), pendekatan Islam perlu ditonjolkan dalam pengurusan organisasi di era ajaran agama mempengaruhi kehidupan dan pekerjaan ketika ini. Bagi beliau pendekatan Islam dalam pengurusan merupakan satu keperluan kerana pekerja yang beragama Islam merupakan komponen terbesar dalam sektor awam di Malaysia. Pendekatan Islam dalam pengurusan juga didapati selari dengan langkah-langkah kerajaan untuk mengislamisasikan agenda pentadbiran dan pengurusan di Malaysia (Endot, 1995).

Khursyid (1991) pernah menyatakan bahawa menjadi satu keharusan bagi umat Islam untuk melihat kembali semua pendekatan pengurusan konvensional yang hanya memberi penekanan kepada peningkatan keuntungan sebagai satu-satunya pengukur kepada pencapaian kerja pekerja dan kemajuan organisasi. Sungguhpun begitu, Islam sebagai agama syumul tidak sekali-kali mengesyorkan pendekatan, mekanisme dan kaedah pengurusan secara kovensional dihapuskan sepenuhnya, melainkan kegiatan sedemikian jelas bertentangan dengan falsafah dan ajaran Islam. Sejarah telah membuktikan bahawa kerajaan Islam mewarisi pengetahuan dan kemahiran dengan menambah pembaharuan penting yang diperoleh dari luar seperti Timur Tengah kuno, Yunani, Parsi dan India (Donald, 1993). Ini adalah kerana asas utama falsafah dan ajaran Islam ialah memberi kesejahteraan dan kebahagiaan dalam membangunkan kehidupan. Sebagai agama wahyu, Islam menyediakan kerangka ajaran yang menyeluruh meliputi segenap aspek dalam kehidupan manusia termasuk kehidupan berorganisasi. 
Bagi Islam, aspek kehidupan berorganisasi diterima sebagai mekanisme yang membolehkan manusia memperoleh dwi kejayaan iaitu dalam bidang kebendaan dan juga kerohanian. Kedua-dua aspek ini amat penting kepada kehidupan di dunia dan juga di akhirat (AlBuraey, 2001). Kedua-dua aspek telah mempengaruhi dorongan dan komitmen umat Islam untuk memberi yang terbaik kepada segenap lapangan yang disertai. Sungguhpun begitu, sehingga kini kajian mengenai sumbangan Islam terhadap pelaksanaan penilaian prestasi Maklum Balas 360 Darjah masih belum diterokai. Mudah-mudahan hasil daripada kajian ini mampu menyediakan satu gantian kepada pengamal dan ahli-ahli akademik bahawa terdapatnya jalan penyelesaian iaitu berlandaskan kepada ajaran Islam terhadap permasalahan yang dihadapi. Berkaitan dengan ini, penilaian prestasi Maklum 360 Dajah perlu diteroka dan diperjelaskan dari kaca mata atau tasawur Islam.

\title{
Tasawur Islam dalam Penilaian Prestasi Maklum Balas 360 Darjah
}

Temuan kajian terdahulu mendapati pelbagai pihak menunjukkan kesangsian mereka terhadap keberkesanan pelaksanaan penilaian prestasi termasuk kaedah Maklum Balas 360 Darjah antaranya Napier dan Latham (1986) dan Banks dan Murphy (1985). Bagi mereka kajian-kajian yang dilakukan hanya mampu memberi sedikit manfaat termasuk kepada pelaksanaan sistem penilaian prestasi Maklum Balas 360 Darjah yang diterima sebagai mekanisme penting dalam menilai prestasi kerja pekerja. Hakikat permasalahan yang dihadapi telah diakui oleh Wiese dan Buckley (1998) apabila mereka menyatakan seperti berikut:

\begin{abstract}
"Until then, businesses will continue to use performance appraisal systems in use today, and hopefully through Divine Providence, the best people will generally rise to the top." (ms. 247).
\end{abstract}

(Sehingga kini, organisasi akan terus menggunakan penilaian prestasi sebagaimana yang digunakan pada hari ini, dan dengan penuh harapan melalui kehematan KeTuhanan, pekerja-pekerja terbaik akan berjaya naik pangkat).

Kehematan ketuhanan sebagaimana yang telah mereka nyatakan merupakan satu pengakuan jujur kerana menyedari kegagalan dan pelbagai permasalahan yang dihadapi semasa dan selepas pelaksanaan penilaian prestasi konvensional termasuk kaedah 
Maklum Balas 360 Darjah. Satu sudut kehematan ketuhanan yang mereka cadangkan adalah selari dengan tuntutan Islam. Walau bagaimanapun, dari sudut pendekatan keTuhanan lain yang dikemukakan berbeza daripada pendekatan keTuhanan yang dituntut oleh Islam. Mengikut Syed Muhammad Al-Naquib (1978) dan Jamal (2002), ketuhanan yang mereka maksudkan adalah dalam kerangka sekularisme barat yang hanya menumpukan kepada aspek ritual, individualistik dan melihat urusan pengurusan organisasi secara terpisah. Sebaliknya, Islam melihat aspek ini dari dua dimensi yang tercantum iaitu aspek kehidupan dunia dan kehidupan di hari akhirat (Ali, 1979). Seterusnya, Sayyid Qutb (1983) memperkukuhkan pandangan ini dengan menjelaskan ajaran Islam tidak memisahkan manusia antara jasad dengan roh serta tidak membezakan antara aspek intelektual dengan kerohanian. Oleh itu, pelaksanaan penilaian prestasi Maklum Balas 360 Darjah perlu dilihat dari aspek yang lebih menyeluruh.

Syed Muhammad Naquib (2005), pernah menyatakan bahawa Islam melihat kehidupan ini meliputi alam dunia dan akhirat, di mana alam kehidupan dunia mesti dikaitkan dengan kehidupan akhirat. Manakala bagi A. Qadir (1981), hukum-hukum yang dibawa oleh Islam meliputi dua aspek penting iaitu pertama melibatkan pertalian dengan masalah akhirat yang melibatkan aspek-aspek akidah dan ibadat. Manakala kedua, berkaitan dengan masalah negara, masyarakat, hubungan sesama manusia yang meliputi masalahmasalah muamalat, munakahat, sahsiah dan lain-lain. Jelas beliau lagi, Islam adalah agama yang seimbang antara tuntutan akhirat dengan tuntutan dunia. Islam juga menyuruh umatnya supaya sentiasa berakhlak mulia dengan membebaskan diri daripada sebarang bentuk diskriminasi dalam menjalankan urusan berorganisasi (Bilal, Ayesha, \& Zareen, 2010).

Menyedari hakikat kepentingan Islam dalam pengurusan maka tasawur Islam hendaklah diterima sebagai suatu sistem yang lengkap meliputi aspek kerohanian, politik, ekonomi dan sosial. Tasawur Islam juga perlu diterima secara bersepadu dalam menyusun atur cara hidup manusia (Abu Ala, 1991). Melalui pengertian dan pemahaman yang menyeluruh mengenai tasawur Islam akan dapat memberi impak dan kesan yang positif ke atas setiap tindakan yang diambil oleh pengurus, pekerja dan pihak-pihak lain yang berkepentingan yang terlibat dalam pelaksanaan penilaian prestasi Maklum Balas 360 Darjah. Semua pihak hendaklah sama-sama tunduk dan patuh kepada perintah Allah SWT sama ada berbentuk suruhan atau larangan. 
Dalam konteks ini tasawur Islam diterima sebagai satu fahaman yang hakiki mengenai Islam bertujuan untuk memperjelaskan secara keseluruhan prinsip asas Islam secara benar dan menyeluruh sehingga menjadi tunjang kepada pandangan hidup yang sebati dengan kehidupan seseorang Muslim (Muhammad Syukri, 2003). Sehubungan ini, pelaksanaan penilaian prestasi Maklum Balas 360 Darjah hendaklah selari dengan tuntutan ajaran yang telah dibawa oleh Islam. Seterusnya, Muhammad Syukri (2003) berpendapat bahawa untuk memenuhi tuntutan tasawur Islam, segala tindakan dan keputusan yang diambil hendaklah berpaksikan kepada tiga prinsip utama iaitu pertama menerima dengan sepenuh keyakinan Allah SWT adalah pencipta, kedua, manusia adalah makhluk Allah SWT dan ketiga segala sumber di mayapada ini juga merupakan makhluk ciptaan-Nya. Bagi beliau, semua makhluk ini hendaklah tunduk dan patuh kepada hukum-hakam yang telah ditetapkan oleh Allah SWT.

Sebagai dorongan utama, ajaran Islam telah menyediakan ganjaran pahala dan dosa di atas ketundukan dan kepatuhan hamba-Nya yang diakui sebagai mekanisme untuk mengawal dan mendorong manusia untuk melakukan yang terbaik. Setiap perbuatan dan keputusan yang dilakukan dengan penuh ikhlas telah dijanjikan dengan ganjaran di dunia juga ganjaran di akhirat. Dalam konteks pelaksanaan penilaian prestasi, penilai yang bertindak selari dengan ajaran Islam akan diberikan ganjaran yang setimpal dengan input yang telah disumbangkan yang dilakukan semata-mata untuk mendapat keredaan Allah serta diterima sebagai satu ibadah (Yousef, 2001). Mereka yakin, selain daripada menilai, mereka juga turut dinilai oleh Allah SWT terhadap setiap keputusan dan tindakan yang telah dilakukan.

Seterusnya, bagi Zahid dan Pervaiz (2004) Islam melihat penyelesaian kepada sesuatu permasalahan bukan hanya berpunca dari luaran (extrinsic) dan permukaan (surface) tetapi memerlukan keprihatinan yang tinggi terhadap dimensi keTuhanan kerana ia akan mempengaruhi tindak tanduk seseorang terhadap pekerjaan yang dilakukan. Lebih-lebih lagi adalah menjadi matlamat pengurus dan pekerja untuk memberi dan juga menerima yang terbaik menurut perspektif Islam.

Untuk mencapai matlamat ini, satu pendekatan baru berkaitan dengan pengurusan organisasi perlu dirangka di mana pengisian dan pelaksanaan yang lebih konkrit dalam bentuk dasar, program dan strategi perlu dibentuk (Wan Liz Ozman, 1996). Dengan lain 
perkataan, pendekatan pengurusan yang lebih menyeluruh selari dengan tuntutan Islam perlu dilaksanakan sebagai pendekatan gantian kepada pendekatan pengurusan konvensional (Mohd Affandi, 1992). Sejajar dengan tuntutan ini, Mansor dan Ali (1998) pernah menyatakan bahawa sudah sampai masanya amalan pengurusan organisasi di Malaysia diterokai dan dilihat dari kaca mata agama Islam.

Pandangan ini selari dengan pandangan Ali (1990) dan disokong oleh Muhammad Syukri Salleh (2002). Bagi mereka, pelaksanaan agenda pengurusan organisasi perlu sejajar dengan tunggak dan prinsip yang telah ditetapkan oleh Islam. Muhammad Syukri (2002) berpendapat kesyumulan pengurusan berteraskan Islam tentunya tidak boleh lepas lari dari bertunjangkan kepada jalinan dengan Allah dan jalinan sesama manusia yang perlu diterima sebagai ilmu fardhu 'ain. Dalam konteks ini, pengurusan organisasi ini akan hanya diterima sebagai tuntutan fardhu 'ain berteraskan Islam jika berjaya memenuhi tuntutan ketiga-tiga hubungan ini (Muhammad Syukri, 2002).

Perkara sama pernah diberi tumpuan oleh Maududur Rahman dan Muhammad Al-Buraey (1992) yang menurut mereka pendekatan pengurusan tradisional lebih terdorong kepada pertimbangan ekonomi yang berobjektifkan keuntungan semaksimum yang mungkin (profit maximization) dengan membelakangkan nilainilai akhlak. Perkara ini diakui kebenarannya apabila Mondy (2010) menyatakan penilaian prestasi merupakan proses yang berorientasikan matlamat bagi memastikan organisasi mendapatkan pulangan produktiviti yang maksimum. Joni Tamkin Borhan, (2008) menyatakan pengurusan merupakan konsep yang multidimensi yang komprehensif mengandungi persoalan ekonomi dan bukan ekonomi serta melibatkan aspek-aspek boleh diukur secara kuantitatif dan kualitatif. Dorongan ini menyebabkan pengurus meletakkan keuntungan mengatasi segala-galanya sehingga sanggup membelakangkan kemanusiaan dan keTuhanan. Ini bertentangan dengan ajaran Islam yang lebih terdorong kepada kehendak kerohanian yang berobjektifkan keuntungan yang berpadanan (reasonable profit). Tayeb (1997:354) pernah menjelaskan keadaan ini sebagaimana berikut:

"Islam, unlike many other religions, is an all-encompassing creed, it governs every aspect of life, public and private, political and economic, and as such is relevant to business activities." 
(Islam, tidak seperti agama-agama yang lain, merangkumi semua sistem, mengawal segenap aspek kehidupan, awam dan persendirian, politik dan ekonomi, begitu juga sesuai dengan aktiviti perniagaan)

Dari sini dapatlah difahami bahawa pengurusan berteraskan Islam meliputi segenap ruang lingkup kehidupan sama ada memenuhi tuntutan fizikal, akal dan rohani yang bertujuan untuk menjamin kesejahteraan kehidupan manusia sejagat. Ajaran yang dibawa oleh Islam telah berjaya meruntuhkan tembok yang memisahkan antara seorang manusia dengan manusia yang lain. Antara tembok yang telah berjaya diruntuhkan ialah ketaksuban kepada bangsa, tanah air, keturunan, warna kulit, pangkat dan status (Danial Zainal Abidin, 2003). Keadaan ini menyebabkan munculnya segolongan dalam organisasi yang sanggup menafikan hak-hak yang wajar diperoleh oleh pekerja-pekerja yang lain. Antara hak-hak berkenaan adalah hak untuk menjaga agama, nyawa, akal, keturunan dan harta benda (Yusof Qaradawi, 1985).

Hak-hak ini didapati bersifat sejagat yang mana bagi Duran (1997) ia melibatkan semua anggota dalam kehidupan berorganisasi. Seterusnya, beliau menjelaskan lagi bahawa prinsip pengurusan berorganisasi dalam Islam bukan hanya melarang tindakan yang boleh memudaratkan orang lain tetapi juga memudaratkan diri sendiri. Prinsip ini boleh dijadikan landasan yang terbaik untuk memastikan tindakan dan keputusan yang diambil tidak mendatangkan kemudaratan kepada diri sendiri dan juga orang lain. Dengan kata lain, pelaku-pelaku utama dalam organisasi hendaklah bersedia membangunkan kehidupan berorganisasi di atas dasar keadilan (Surtahman, 1993), dengan matlamat utama untuk memperoleh keredaan Allah SWT serta mengembalikan fungsi manusia sebagai hamba dan khalifah-Nya (Muhammad Syukri, 2002).

Sungguhpun begitu, Muhammad Syukri (2002) mendapati perbincangan mengenai pengurusan organisasi berlandaskan Islam adalah masih baru dan ia perlu terus digilap dan diperkemaskan. Bagi beliau terdapat dua langkah yang boleh memperkemaskan ilmu mengenai pengurusan Islam iaitu pertama dengan membentuknya dari perspektif yang lebih holistik dan kedua melengkapkannya dengan semua aspek pengurusan secara lebih menyeluruh iaitu bermula dari aspek teoritis sehingga kepada aspek-aspek pelaksanaannya. 
Bagi menyokong usaha sedemikian, Al-Buraey (2001) telah mengenal pasti lima faktor utama yang mendorong kepada pembinaan model dalam pengurusan dari perspektif Islam iaitu pertama, keperluan umat Islam untuk memahami teori, nilai dan amalan berkaitan dengan kehidupan berorganisasi. Kedua, umat Islam hendaklah kembali kepada prinsip asas pengurusan yang mengutamakan elemen semangat, sejarah dan kehidupan yang diamalkan sejak zaman Nabi Muhammad SAW dan para Khalifah.

Faktor ketiga adalah peranan umat Islam sendiri yang telah membuktikan keyakinan untuk mengamalkan kaedah ini untuk mengembalikan semula kegemilangan tamadun Islam. Faktor keempat didorong oleh pengalaman yang pernah dialami oleh umat Islam melalui pelbagai model pengurusan konvensional telah terbukti gagal untuk membawa kemakmuran kepada kehidupan mereka. Bahkan ramai dalam kalangan intelektual Barat sendiri yang telah membuat pengakuan secara terbuka mengenai kegagalan ini sehingga tercetusnya fenomena baru yang mahukan pendekatan agama kembali dipersadakan dengan apa yang telah diistilahkan sebagai the global resurgence of religion (Azzam \& Esposito, 2000).

Faktor terakhir yang mendorong pembinaan model pengurusan Islam adalah penciptaan model Islam daripada sumber utama pengurusan Islam. Sungguhpun begitu, ia hendaklah disesuaikan dengan pemikiran kontemporari dengan menggunakan teknik, alat dan teknologi kontemporari serta penglibatan pakar dan pengamal kontemporari melalui khidmat nasihat dan bantuan. Bertolak dari sini, kajian secara teoritis perlu dilakukan terhadap pendekatan penilaian prestasi Maklum Balas 360 Darjah dari perspektif Islam.

\section{Pendekatan Penilaian Prestasi Maklum Balas 360 Darjah dari Perspektif Islam}

Mengikut ajaran Islam, perbincangan mengenai penilaian prestasi Maklum Balas 360 Darjah bukan merupakan sesuatu perkara yang baharu. Ia telah diperkenalkan seawal kejadian manusia itu sendiri. Bagi memastikan manusia bertindak selari dengan tuntutan-Nya, Allah SWT telah melantik dua malaikat iaitu Raqib dan 'Atid untuk mencatat segala amal perbuatan manusia yang dilakukan secara berterusan, menyeluruh dan bebas daripada sebarang bentuk kelalaian. Firman Allah SWT yang bermaksud: 
"Bagi setiap manusia ada malaikat-malaikat bertugas silih berganti dari hadapannya dan dari belakangnya, yang mengawas dan menjaganya (daripada sesuatu bahaya) dengan perintah Allah....."

(Surah al-Ra'd 13: 11)

Natijah daripada amal perbuatan mereka akan diberikan ganjaran pahala atau dosa yang bakal melayakkan mereka untuk memasuki syurga atau neraka Allah SWT hasil daripada setiap pekerjaan yang dilakukan bersaksikan anggota mereka sendiri. Firman Allah yang bermaksud:

"Bahkan manusia itu, (anggotanya) menjadi saksi terhadap dirinya sendiri"

(Surah al-Qiyāmah 75: 14)

Bahkan di hari pengadilan segala anggota milik manusia akan menjadi saksi terhadap segala pekerjaan yang mereka lakukan semasa menjalani kehidupan di dunia. Dalam Islam, urusan pekerjaan telah diberi penekanan seawal sejarah kejadian manusia itu sendiri. AlQur'an pernah menceritakan dua orang anak kepada Nabi Adam a.s yang telah mempelopori dua bidang pekerjaan utama yang terdapat hari ini iaitu Habil mempelopori lapangan pertanian dan Qabil mempelopori lapangan ternakan sebagaimana firman Allah SWT yang bermaksud:

"Ceritakanlah (wahai Muhammad) kepada mereka kisah dua
oranganakAdam (Habildan Qabil) yang telahberlakudengan
sebenarnya. Iaitu ketika mereka berdua mempersembahkan
korban (untuk mendampingkan diri kepada Allah), lalu
diterima korban salah seorang antara kedua-dua mereka
(Habil) dan tidak diterima (korban) daripada yang
lain (Qabil). Qabil berkata, "Sesungguhnya aku akan
membunuhmu!" (Habil) menjawab, "Sesungguhnya Allah
hanya menerima (korban) daripada orang yang bertaqwa."

(Surah al-Mā'idah 5: 27)

Ayat di atas telah menjelaskan bagaimana Allah SWT menilai prestasi kerja yang telah dibuktikan oleh Qabil dan Habil. Dalam penilaian berkenaan, Allah SWT telah mengambil kira kualiti korban 
yang telah dibuktikan oleh kedua-dua mereka dan keikhlasan dan ketaqwaan yang telah ditunjukkan. Ali (2005) menyatakan penilaian prestasi dalam Islam perlu berdasarkan ajaran Al-Quran dan Sunnah Rasulullah SAW. Bagi tujuan ini, Islam telah menyediakan pendekatannya sendiri dalam penilaian prestasi Maklum Balas 360 Darjah. Pendekatan yang disediakan adalah untuk memastikan pelaksanaannya dapat dilaksanakan selari dengan syariat yang telah ditetapkan. Setiap penilai perlu menerima syariat sebagai pendorong, petunjuk dan pembimbing semasa melakukan penilaian prestasi yang telah diamanahkan. Penilai perlu meletakkan sepenuh keyakinan bahawa Islam merupakan agama yang paling kontemporari dan sesuai pada semua tempat, mampu menyelesaikan segala masalah, dalam pelbagai situasi dan pada sepanjang zaman. Mereka perlu sedar objektif utama agama Islam adalah untuk meningkatkan tahap kehidupan manusia agar lebih selesa dan gembira (Afzal-UrRahman, 1994). Seterusnya, Islam menyarankan kepada umatnya agar selalu menilai atau muhasabah diri sekiranya ingin berjaya di dunia dan di akhirat.

\section{Pendekatan Tiga Segi Pelaku Penilaian Prestasi Maklum Balas 360 Darjah}

Pendekatan Tiga Segi Pelaku penilaian prestasi Maklum Balas 360 Darjah dari perspektif Islam cuba mengetengah satu pendekatan yang terkeluar daripada pendekatan lazim. Dalam konteks ini, pelaku utama adalah manusia (Muhammad Syukri, 2001; 2002). Mengikut beliau, manusialah yang bakal terlibat dan mereka jugalah yang bakal menerima kesan daripada usaha-usaha yang telah dilakukan. Dalam konteks pelaksanaan penilaian prestasi Maklum Balas 360 Darjah manusia yang terlibat dikategorikan kepada tiga golongan iaitu pengurus atasan, penilai dan pihak-pihak yang dinilai. Ketiga-tiga golongan ini perlu memainkan peranan secara simbiosis iaitu saling sokong-menyokong, saling bantu-membantu dan saling bertindak sebagai check and balance.

Ketiga-tiga pelaku ini perlu memastikan kesan akhir daripada pelaksanaan mampu memenuhi tuntutan secara menegak mereka dengan Allah SWT (hablumminallah), tuntutan secara mendatar sesama manusia (hablumminannas) dan juga hubungan dengan alam (hablumminalalamin) dengan satu tujuan iaitu memperoleh keredaan daripada Allah SWT. 
IJMS 20 (1), 203-230 (2013)

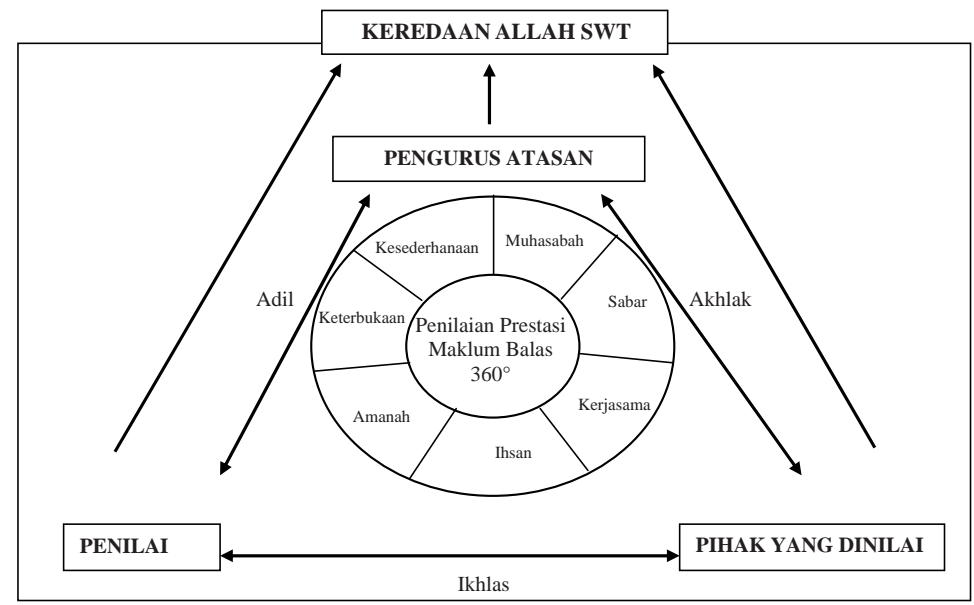

Rajah. Pendekatan tiga segi penilaian prestasi maklum balas 360 darjah dari perspektif Islam.

Pelaku-pelaku ini perlu dilihat sebagai manusia yang telah diberi kelebihan oleh Pencipta untuk memobilisasi sumber bagi memastikan penilaian yang dilaksanakan berdasarkan ajaran al-Quran, Sunnah Rasulullah SAW, qias dan ijma' ulama (Ali, 2005). Sebagai manusia, mereka bertanggungjawab atas apa yang dilakukannya dan tiada siapa yang bertanggungjawab atas kesilapan orang lain dan pencapaian mereka akan dinilai secara berterusan dan menyeluruh.

Untuk memastikan pencapaian kerja yang terbaik, pelaku-pelaku ini perlu memiliki keterampilan diri yang baik, pemikiran yang matang, ketenangan dalam mengurus nafsu dan kemantapan rohani sehingga diyakini pihak-pihak yang menilai dan dinilai. Mereka perlu sentiasa berusaha untuk mengubah kualiti kehidupan berorganisasi ke arah yang lebih baik dengan mengubah proses dan juga hasil kerja dengan mengubah sikap, cara berfikir, cara melaksanakan tugas sehingga berjaya memartabatkannya sebagai satu ibadat.

Mereka akan lebih berhati-hati dalam apa jua perkara yang akan mereka lakukan agar tidak tergelincir daripada landasan yang telah ditetapkan (Endang, 1986). Afzal-Ur-Rahman (1994) mengingatkan supaya pelaku perlu sedar bahawa matlamat utama memakmurkan organisasi adalah untuk meningkatkan kualiti kehidupan berorganisasi 
agar pekerja gembira dan selesa dengan tugas yang mereka laksanakan (Rahmad Sukor \& Gooi, 2005). Justeru, segala tindak tanduk mereka hendaklah menjurus ke arah mencapai kemakmuran organisasi yang hakiki.

Untuk mencapai tujuan ini, pelaku-pelaku perlu mengutamakan keadilan dalam setiap tindak-tanduk dan keputusan yang diambil. Menurut Khaliq (2004), keadilan Islam berdasarkan kepada tiga prinsip utama iaitu adil, insaf dan ihsan. Dengan mematuhi prinsipprinsip ini akan memberi jaminan kepada dua bentuk ganjaran iaitu ganjaran kebendaan dan ganjaran yang berbentuk superfisial. Melalui ganjaran yang berbentuk superfisial atau ukhrawi akan mendorong pelaku untuk terus memperingkatkan kualiti penilaian pencapaian kerja yang dilakukan.

\section{Kriteria Asas Pelaksanaan Penilaian Prestasi Maklum Balas 360 Darjah dari Perspektif Islam}

Bagi memastikan pelaksanaan penilaian prestasi Maklum Balas 360 Darjah dapat dilakukan dengan jayanya, setiap penilai perlu memenuhi kriteria-kriteria berikut ialah:

\section{Berakhlak}

Nilai akhlak yang mulia merupakan satu ciri keindahan yang terdapat dalam kehidupan manusia. Menurut Mustaq (2001) akhlak merujuk kepada sifat kemanusiaan yang tinggi dan mulia. Ciri ini jugalah yang membezakan antara manusia yang berperadaban dengan manusia yang jahil. Bagi Hassan (1998), kehebatan seseorang tidak sahaja diukur dengan kemajuannya tetapi juga keupayaannya mengamalkan budi bahasa dan budi pekerti yang mulia. Akhlak diterima sebagai cetusan yang terpancar dari amalan yang sebati di dalam jiwa seseorang. Malahan ia juga dijadikan sebagai salah satu tunjang penting yang perlu ada dalam pelaku-pelaku penilaian prestasi Maklum Balas 360 Darjah.

Al-Quran telah menggariskan beberapa amalan yang melambangkan kemuliaan budi yang perlu dimiliki oleh setiap pelaku. Antaranya ialah Rasulullah SAW telah mewajibkan agar seseorang sentiasa berakhlak mulia seperti yang tua perlu dihormati dan yang muda perlu disayangi. Rasulullah SAW pernah bersabda yang bermaksud: 
"Sesiapa yang tidak menyayangi kanak-kanak dan tidak menghormati orang yang lebih tua, maka ia bukan daripada golongan kami."

(Hadis Riwayat Bukhari)

Sebaliknya, Islam melarang umatnya saling berburuk sangka, memfitnah, mengumpat, mengeji, mencari keaiban orang lain, merendahkan orang lain, berlagak sombong, angkuh, riak dan membangga diri. Semua larangan ini dijelaskan oleh Allah SWT di dalam ayat:

"Wahai orang-orang yang beriman! Janganlah sesuatu puak (dari kaum lelaki) mencemuh dan merendah-rendahkan puak lelaki yang lain. Mungkin puak yang dicemuh itu lebih baik daripada mereka. Dan janganlah pula sesuatu puak dari kaum perempuan mencemuh dan merendah-rendahkan puak perempuan yang lain. Mungkin puak yang dicemuh lebih baik daripada mereka. Dan janganlah kamu menyatakan keaiban setengah yang lain..."

(Surah al-Hujurāt 49: 11).

Mereka perlu membantu pekerja agar menambak baik pencapaian kerja dengan terus meningkatkan mutu kerja dan produktiviti. Keduadua aspek ini mampu dilaksanakan dengan memberi penumpuan kepada prinsip kesempurnaan (al-Itqan), pembaharuan (at-tajdid) dan inovasi (al-ikhtikar) (Wan Liz Ozman, 1996).

Memiliki akhlak yang mulia akan dapat meletakkan pelaku disenangi oleh pelbagai pihak. Keintiman antara mereka akan lebih akrab kerana mereka lebih bersikap bertanggungjawab, bertolak ansur dan saling memahami. Pelaku yang berakhlak mulia dan amanah amat disenangi oleh Allah SWT. Mereka akan bertindak secara konsisten dalam menjalankan tugas dengan cekap dan penuh tanggungjawab kerana ikatannya hanyalah kepada Allah SWT. Ketinggian akhlak yang didokong oleh ketakwaan mereka terhadap Allah SWT akan menjadikan mereka seorang yang bersedia untuk memberi perkhidmatan untuk kebaikan pekerja yang dinilai dengan tujuan mendapat keredaan dan mengelakkan dari kemurkaan Allah SWT.

\section{Berlaku Adil}

Penilai perlu mengutamakan keadilan organisasi semasa melaksanakan penilaian prestasi Maklum Balas 360 Darjah. Menurut Yusof (1983), berlaku adil sepenuhnya bukan hanya untuk dilihat sebagai adil oleh 
pihak lain tetapi adalah untuk membuktikan keadilan dilakukan dengan penuh keikhlasan dari segi hati dan nurani hanya untuk memperoleh ganjaran keredaan daripada Allah SWT. Menyedari kepentingan keadilan dalam Islam, Mohamed Barween (2002) menyatakan aspek ini merupakan antara sepuluh hak asasi manusia yang perlu dipenuhi dan dihormati. Hak-hak lain yang dimaksudkan ialah hak manusia untuk mendapat kehidupan, hak manusia untuk mendapat ketenangan, hak manusia untuk membuat pilihan, hak manusia untuk mendapat kesamarataan di bawah undang- undang, hak manusia untuk mendapat asas kepada keperluan kehidupan, hak manusia untuk mendapat kebebasan bersuara, hak manusia untuk bersendirian, hak manusia untuk mendapat hak milik dan hak manusia untuk memprotes.

Begitu juga, dalam melaksanakan penilaian prestasi Maklum Balas 360 Darjah memerlukan penilai untuk membuat keputusan yang berkaitan dengan pengagihan tugas dan penentuan ganjaran yang perlu dilakukan dengan seadil yang mungkin. Hal ini kerana keadilan perlu diterima sebagai suatu amanah yang patut dipenuhi (Azman, 2001). Lantaran daripada itu, keadilan Islam dalam pelaksanaan penilaian prestasi Maklum Balas 360 Darjah bertujuan untuk memberikan kesaksamaan kepada semua pekerja. Perkara bertepatan dengan ajaran Islam yang mengiktiraf perbezaan jantina, etnik, warna kulit, bentuk fizikal, personaliti, bahasa dan kebudayaan kerana perbezaan berkenaan dijadikan oleh Allah untuk tujuan saling kenal mengenali antara satu dengan yang lain (Mohd Nasir, 2005).

Pengurus perlu sentiasa menegakkan keadilan. Ini kerana mengutamakan keadilan adalah serlahan daripada sifat Allah SWT iaitu Maha Adil. Keadilan manusia akan mengelak mereka daripada melakukan kezaliman dan penindasan organisasi dan ummah. Yang pasti semua pihak mahukan jaminan keadilan dengan memenuhi hak-hak yang layak mereka diperoleh. Hal ini kerana mengikut ajaran Islam, perbezaan yang bersifat lahiriah atau dibuat, membawa kepada perbezaan kemanusiaan seperti membezakan manusia dari segi bahasa, keturunan, warna kulit, kelas dan kehidupan sosial amatlah dilarang sama sekali. Apabila manusia dipandang berbeza dari segi status, pangkat, warna kulit dan bahasa secara tidak langsung keadilan terhadap mereka pun berbeza-beza juga (Sidi, 1986). Kesamaan manusia di sisi Allah SWT menyebabkan manusia berada pada taraf yang sama, mendapat hak yang sama rata dan keadilan yang sama. 
IJMS 20 (1), 203-230 (2013)

\section{Sentiasa Ikhlas}

Sesuatu tugas juga mestilah dilaksanakan dengan ikhlas dan jujur dan bukannya bertujuan untuk kepentingan diri sendiri atau tujuantujuan lain selain daripada mengharapkan keredaan daripada Allah SWT. Rasulullah saw pernah bersabda yang bermaksud:

"Sesungguhnya tidak dikira amalan kecuali dengan niat dan tiap-tiap orang akan mendapat apa yang diniatkan. Maka barang siapa yang (menjadikan) hijrahnya kepada Allah dan Rasul-Nya dan barang siapa yang menjadikan hijrahnya untuk mendapatkan faedah dunia atau untuk mengahwini seorang perempuan, hijrahnya adalah untuk apa yang dihijrahkan."

(Hadis Riwayat Bukhari dan Muslim)

Niat ini akan mempengaruhi keikhlasan tindakan seseorang. Niat yang ikhlas serta disusuli dengan perbuatan yang baik dikira sebagai amal ibadat yang akan mendapat ganjaran bukan sahaja di dunia tetapi juga di akhirat. Firman Allah yang bermaksud:

"Katakanlah: Sesungguhnya sembahyangku, ibadatku, dan matiku semuannya bagi Allah, Tuhan semesta alam."

(Surah al-An'ām 6: 162).

Sekiranya seseorang tidak ikhlas dalam melaksanakan sesuatu pekerjaan ia akan menjadi punca kepada berlakunya manipulasi dan mempolitikkan fungsi penilaian prestasi. Penilai perlu insaf setiap tindakan mereka akan dinilai di sisi Allah SWT. Perkara ini pernah diberi amaran oleh Allah SWT melalui firman-Nya yang bermaksud:

"Sesiapa yang melakukan kesalahan (kejahatan) sebesar atom pun akan dilihatNya"

(Surah al-Zalzalah 99: 8)

\section{Sifat-Sifat yang Perlu Dimiliki oleh Penilai}

Bagi berhadapan dengan masalah semasa melaksanakan penilaian prestasi dan kesan-kesan buruk akibat daripadanya, Islam telah mengenal pasti beberapa strategi yang perlu dihayati oleh setiap penilai. Antara strategi-strategi yang dimaksudkan adalah seperti berikut: 


\section{Mengutamakan Kesabaran}

Penilai perlu turut memanifestasikan sifat sabar mereka terhadap gelagat pekerja, pelanggan dan pihak-pihak lain yang terlibat dalam pelaksanaan penilaian prestasi 360 Darjah. Penilai yang sabar menerima segala cabaran dengan tenang, tidak mudah gelabah dan tahu bila, kenapa dan bagaimana sesuatu tindakan perlu diambil dengan penuh bijaksana. Semangat dan ketabahan yang ada pada mereka menunjukkan kewibawaan dalam menjalankan tugas yang telah diamanahkan. Penilai sedemikian juga tidak mudah hilang pedoman atau mencampakkan diri mereka ke lembah kekecewaan apabila berhadapan dengan kegagalan kerana kesabaran yang dimiliki bakal membimbing dan mendorong mereka untuk terus melakukan yang terbaik.

Di samping itu, mereka tidak mudah berpuas hati dengan pencapaian kerjanya walaupun diberi penghargaan atau pujian atau sanjungan. Sifat tidak berpuas hati dengan pencapaian semasa akan menyebabkan mereka terus berusaha untuk memastikan kemakmuran organisasi yang berterusan. Mereka perlu yakin bahawa kesabaran mereka menghadapi cabaran dan rintangan akan mendatangkan kesan yang baik untuk jangka masa dekat atau jangka masa yang panjang. Bagi mereka setiap kegagalan yang dilalui merupakan satu pengajaran yang sangat berharga.

\section{Mengamalkan Sikap Bekerjasama}

Masalah berkaitan dengan pelaksanaan penilaian prestasi Maklum Balas 360 Darjah boleh diminimumkan dengan adanya kerjasama antara pekerja, penilai dan pengurus atasan (Abuznaid, 2006). Bagi Tayeb (1997) kerjasama yang wujud akan meningkatkan semangat kerja berpasukan, mewujudkan suasana saling sokong menyokong dan boleh meningkatkan produktiviti organisasi. Kesedaran untuk terus saling bekerjasama hendaklah berdasarkan kepada semangat persaudaraan (ukhuwah) bertujuan untuk sama-sama meningkatkan kualiti organisasi. Kerjasama yang perlu diberikan hendaklah melangkaui warna kulit, bangsa, sempadan geografi, keturunan dan status. Allah SWT pernah menjelaskan melalui firman-Nya yang bermaksud:

"Dan tolong menolonglah kamu dalam mengerjakan kebajikan dan taqwa dan jangan tolong menolong dalam berbuat dosa dan kerosakan." 


\section{Berihsan}

Ihsan bermaksud melaksanakan tugas dengan cekap dan berkesan. Mereka yang memiliki sifat ihsan akan penuh yakin bahawa Allah SWT sentiasa memerhati kerja yang dilakukan (Yusof Al Qaradawi, 1985) sehingga menjurus mereka menyerahkan diri dalam memberi sepenuh perkhidmatan kepada Allah SWT (Syed Muhammad Naquib, 1978). Penilai yang memiliki sifat ini akan lebih bersedia untuk memaafkan kesilapan yang dilakukan oleh pekerja (Maududur Rahman \& Muhammad Al-Buraey, 1992).

Keihsanan yang dibuktikan hendaklah berdasarkan kepada keilmuan, kemahiran, pengalaman dan kemampuan yang dimiliki oleh penilaipenilai yang terlibat. Penilai-penilai yang menitik beratkan nilai keihsanan tidak akan melakukan aktiviti ini secara sambil lewa dan acuh tak acuh. Allah SWT telah menjanjikan ganjaran yang baik kepada mereka yang melakukan pekerjaan dengan baik, sempurna dan dengan penuh keihsanan. Firman-Nya yang bermaksud:

"Sesungguhnya Allah tidak menghilangkan pahala orangorang yang berusaha memperbaiki amalnya."

(Surah at-Tawbah 9: 120)

Di samping itu, bagi memastikan kecekapan dan keberkesanan penilai tidak sepatut bertindak secara ad hoc, gopoh dan tidak melihat secara menyeluruh kesan daripada tindakan dan keputusan yang telah diambil. Mereka perlu sedar kesilapan dalam memilih strategi akan menyebabkan organisasi menghadapi bebanan kewangan dan juga bukan kewangan.

\section{Sentiasa Amanah}

Amanah adalah prinsip akauntabiliti kepada Allah SWT. Bagi Ab Mumin dan Fadillah (2008) amanah perlu diterima sebagai mekanisme menghargai kepercayaan yang telah diberikan oleh seseorang yang perlu dilakukan dengan sebaik mungkin. Pandangan ini selari pendapat Mohd Asri dan Mohd Nor (2010) yang merujuk amanah sebagai perbuatan tidak melampau dalam urusan yang dipertanggungjawabkan ke atas seseorang. Mereka yakin segala usaha yang diambil untuk memakmurkannya merupakan satu ibadat kepada Allah SWT. (Kazmi \& Ahmad, 2006). 
Begitu juga dalam melaksanakan penilaian prestasi, penilai perlu menunaikan amanah ini sebagai satu tanggungjawab kepada pekerja untuk dilaksanakan dengan sebaik yang mungkin (Hanafi \& Sallam, 2006). Bagi Rashid, Mohd Yadman dan Salahudin (2008) pelaksanaan penilaian prestasi yang dilakukan dengan penuh amanah dilakukan dengan bersandarkan kepada fakta yang tepat. Mereka perlu mengelak daripada membuat keputusan yang dipengaruhi oleh kepentingan diri sendiri. Muhammad Nubli (2008) berpendapat kepentingan sifat amanah berkait rapat dengan pengagihan sumber organisasi. Justeru, penilai sebagai pemegang amanah tiada hak untuk memanipulasi sumber organisasi dengan menafikan hak yang perlu diberikan kepada pekerja. Mereka perlu akur pelaksanaan penilaian prestasi Maklum Balas 360 Darjah yang melibatkan persoalan dan masa depan pekerja perlu dilaksanakan dengan penuh amanah (Rashid, Mohd Yadman, \& Salahudin, 2008).

\section{Keterbukaan}

Penilai perlu sentiasa bersikap terbuka. Keterbukaan mereka akan menyebabkan mereka bersikap lebih sensitif, fleksibel, kreatif dan mempunyai perasaan ingin tahu yang tinggi. Pada masa yang sama mereka lebih bersedia untuk menerima teguran, cadangan dan berlapang dada apabila bersemuka dengan pelbagai pihak yang berkepentingan. Mereka juga akan lebih bersedia untuk menerima maklum balas daripada kumpulan sasaran. Sifat keterbukaan yang dimiliki akan menyebabkan pelbagai pihak lebih bersedia untuk menyuarakan pandangan kerana mereka tahu terdapatnya perasaan saling percaya mempercayai dalam kalangan mereka.

Sikap keterbukaan yang ada pada mereka akan dapat meningkatkan keberkesanan aliran maklumat kerana kesediaan mereka untuk berkomunikasi dengan kumpulan sasar yang berada dipelbagai peringkat dari yang serendah-rendahnya hinggalah ke peringkat yang setinggi-tingginya. Sikap sebegini sudah tentu dapat mengelakkan mereka daripada berasa selesa dengan pencapaian semasa serta mengutamakan status quo kerana sentiasa memperoleh input baru sama ada dalam bentuk cadangan atau kritikan. Mereka juga lebih proaktif terhadap perkembangan teknologi dan penciptaan baru. Keterbukaan akan memungkinkan mereka mempelajari sesuatu yang baru tanpa mengambil kira sumber dari mana datangnya kebenaran berkenaan. 


\section{Kesederhanaan}

Dalam konteks pelaksanaan penilaian prestasi Maklum Balas 360 Darjah, kesederhanaa adalah sikap penilai yang menolak keterlaluan sama ada dalam menetapkan sesuatu peraturan, sasaran dan ganjaran. Mengikut Yusof Al-Qaradawi (1984), Islam adalah manhaj yang sederhana dalam setiap perkara sama ada antara persepsi dan iktikad, ibadat dan cara melaksanakannya, pada akhlak dan cara hidup dan pada muamalat dan perundangan. Umat Islam merupakan umat yang menjadi teladan (qudwah) kerana keseimbangannya. Dengan memiliki sifat kesederhanaan akan mengelak penilai daripada mengambil tindakan yang melampau terhadap pekerja yang tidak disukai dengan memastikan mereka tidak membelakangkan kehidupan di akhirat (Mohd Nasir, 2005). Rasulullah SAW pernah bersabda yang bermaksud:

\section{"Jauhilah melampau dalam agama. Sesungguhnya rosaknya orang-orang sebelum kamu kerana melampau dalam agama."}

(Hadis Riwayat Ahmad)

Kesederhanaan juga melambangkan kecemerlangan penilai kerana kebolehan mereka untuk mengimbangkan keperluan dunia dan akhirat yang berteraskan keikhlasan yang akan memberikan erti dan kesan yang baik kepada pelbagai pihak (Mohd Fuad, 1985). Mereka tidak akan bersikap keterlaluan dalam membuat pertimbangan dan tindakan dengan memastikannya selari dengan ajaran Islam yang mahukan mereka sentiasa bersederhana.

\section{Bermuhasabah}

Islam menggariskan muhasabah sebagai asas kepada rukun Iman iaitu mengimani Yaum al-Hisab. Penilai semestinya melakukan aktiviti penilaian dengan penuh rasa tanggungjawab dan berwaspada tentang suatu hari di mana semua sahsiah dan tindak-tanduk akan dikira dan dihisab. Bagi Hassan al-Banna (1998) muhasabah merupakan suatu bentuk amalan kerohanian untuk mengubat jiwa dan ianya turut memberi implikasi positif kepada jasmani manusia. Menurut beliau jiwa manusia merupakan sumber sistem, fikiran, konsep dan pembentukan sahsiah. Amalan muhasabah perlu bagi mengukur tahap dan kesan pelaksanaan aktiviti penilaian ke atas individu serta organisasi. Dalam masa yang sama membantu penilai dalam menilai kekuatan, kelemahan, peluang dan ancaman. 
Penilai perlu membuat penilaian terhadap pelaksanaan tugas dan tanggungjawab secara berterusan. Dalam melaksanakan tugas ini, mereka hendaklah sentiasa bermuhasabah terhadap tindakan dan keputusan yang diambil serta sedar natijah daripadanya. Tujuan penilaian dibuat bukan untuk mencari kelemahan yang boleh menggagalkan organisasi sebaliknya bertujuan untuk membolehkan pekerja untuk terus memperteguhkan kekuatan.

Allah SWT menjanjikan kepada orang yang sentiasa berwaspada daripada melakukan perkara yang boleh mendatangkan kemurkaan AllahSWT. Mereka perlu sentiasa bermuhasabah diribagi memastikan mereka mendapat kecemerlangan di dunia dan di akhirat. Penilai yang sentiasa berwaspada dan prihatin terhadap urusan mereka akan beroleh kejayaan dan kemenangan.

\section{Keredaan Allah}

Sungguhpun pelaksanaan penilaian prestasi Maklum Balas 360 Darjah yang dilakukan adalah bertujuan mendapatkan keuntungan organisasi sama ada dalam bentuk kewangan atau bukan kewangan tetapi kegiatan ini juga merupakan alat untuk mencapai matlamat yang terunggul iaitu memperoleh keredaan Allah (marthatillah). Bagi penilai sedemikian, usaha untuk mendapatkan keredaan Allah SWT merupakan matlamat hakiki penglibatan mereka dalam pengurusan organisasi. Mereka akan sentiasa mempersoalkan tindakan dan keputusan sejauh mana akan mendekatkan diri atau menjauhkan diri daripada keredhaan Allah.

Di samping memperoleh keuntungan mereka perlu berusaha mengagihkan keuntungan yang diperoleh secara adil dengan pelbagai pihak yang berkepentingan. Keredaan yang diperoleh daripada Allah SWT akan memberi ruang kepada mereka untuk terus melipatgandakan usaha bagi memastikan berlakunya penambahbaikan dan kemajuan yang berterusan. Allah telah menjanjikan kejayaan berterusan kepada golongan yang sentiasa tunduk dan patuh kepada ajaran-Nya. Firman Allah SWT yang bermaksud:

"Sekiranya penduduk suatu negeri itu beriman dan bertaqwa, nescaya Kami akan membuka kepada mereka (pintu-pintu pengurniaan) yang melimpah-limpah berkatnya dari langit dan bumi." 


\section{Rumusan}

Islam telah menyediakan pendekatannya sendiri dalam pelaksanaan penilaian prestasi Maklum Balas 360 Darjah. Pendekatan yang disediakan adalah untuk memastikan pelaksanaan yang menyeluruh selari dengan syariat yang telah ditetapkan. Dalam Islam penilaian prestasi Maklum Balas 360 Darjah diterima sebagai mekanisme untuk menilai pencapaian setiap tugas dan tanggungjawab yang telah diamanahkan agar selari dengan tuntutan Islam. Yang paling utama, anggota yang menilai dan yang dinilai perlu memiliki ciriciri yang boleh membawa mereka ke arah memperoleh keredaan daripada Allah SWT.

Semasa melaksanakannya mereka akan meletakkan sepenuh keyakinan bahawa Islam merupakan agama yang paling kontemporari dan sesuai pada semua tempat, dalam pelbagai situasi, di sepanjang zaman serta mampu menyediakan jalan keluar terhadap pelbagai permasalahan yang berpunca daripada kelemahan manusia. Mereka perlu sedar natijah daripada pelaksanaan yang selari dengan ajaran Islam bakal membolehkan mereka memperoleh kejayaan hakiki yang bersifat holistik.

\section{Rujukan}

A. Qadir Audah. (1981). Islam di antara kejahilan umat dan kelesuan ulamak. Kuala Lumpur: IIFSO.

Abbas, J., Gibbs, M., \& Camp, R. (2000). Human resource strategy: The ten commandment perspective. The International Journal of Sociology and Social Policy, 20(5/6), 114-133.

Ab Mumin., Ab Ghani, \& Fadillah Mansor. (2008). Dimensi pengurusan Islam mengurus kerja dan mengurus modal insan. Kuala Lumpur: Penerbit Universiti Malaya.

Abu A'la Maududi, Sayyid. (1991). The Islamic movement: Dynamics of values, power and change. Khurram Murad (Ed.). Leicester, UK: The Islamic Foundation.

Abuznaid, S. (2006). Islam and management: What can be learned?

Thunderbird International Business Review, 48(1), 125-39.

Al-Bukhari. (1994). Sahih al-Bukhari. Beirut: Dar al-Fikr.

Al-Buraey, M. A. (2001). The Islamic model of administration:

Strategy, implementation and implications. Managerial Finance, 27(10/11), 5-24. 
Afzal-Ur-Rahman. (1994). Doktrin Ekonomi Islam (Jld.1) (Terj.). (Mustafa Kassim. Pentj.). Kuala Lumpur: Dewan Bahasa dan Pustaka.

Albright, M., \& Carr, C. (1997). 101 Biggest mistakes managers make and how to avoid them. United States of America: Prentice Hall Press.

Ali, A. (2005). Islamic perspectives on management and organization.

Edward Elgar: Cheltenham and Northampton, MA.

Ali Jarishah. (1990). Kehormatan hak-hak insan menurut Islam.

(Mohd Marzuki Shafie Pentj.). Kuala Lumpur: Dewan Bahasa dan Pustaka.

Ali Shari'ati. (1979). On the sociology of Islam. Berkeley: Mizan Press.

Mohd Asri Abdullah, \& Mohd Nor Mamat. (2010). Islam dan pengurusan: Menagani arus globalisasi. Shah Alam: UPENA.

Azman Che Omar. (2001). Pekerjaan di Malaysia dari perspektif Islam. Kuala Lumpur: Dewan Bahasa dan Pustaka.

Azzam Tamimi, \& John L. E. (2000). Islam and secularism in the Middle East. London: Hurst and Company.

Banks, G., \& Murphy, K. (1985). Toward narrowing the researchpractice gap in performance appraisal. Personnel Psychology, 38, 335-345.

Baron, J. N., \& Kreps, D. M. (1999). Strategic human resources: Frameworks for general managers. New York: John Wiley \& Sons.

Mohamed Barween. (2002). The fundamental human rights: An Islamic perspective. The International Journal of Human Rights, 6(1), 61-78.

Bilal Khan, Ayesha Farooq, \& Zareen Hussain, (2010). Human resource management: An Islamic perspective. Asia-Pacific Journal of Business Administration, 2(1), 17-34.

Comerford, H. (2002). Findings Report Respectful Workplace Project. Government of Newfoundland and Labrador, Mimeo.

Dacri, R. (2005). Unwanted, disliked, dishonest: Performance appraisals. Retrieved from http://business.mainetoday.com

Danial Zainal Abidin. (2003), Islam agama unik lagi unggul. Dlm. Danial Zainal Abidin. Empayar minda muslim: Modul tarbiah asas alat ketiga. Pahang: PTS Publication and Distributors.

Deondra, S. C. (2006). Human-resource professionals' perceptions of organizational politics as a function of experience, organizational size, and perceived independence. The Journal of Social Psychology, 146(6), 717-732.

Derven, M. G. (February, 1990). The paradox of performance appraisals. Personnel Journal, 69, 107-111. 
Hill, D. R. (1993). Islamic science and engineering. Edinburgh: University Press.

Duran, K. (1997). Leonard Swidler's draft of a global ethic: A Muslim perpective. Center for Global Ethics, Philadelphia, PA.

Edwards, M. (1989). Making performance appraisal meaningful and fair. Business, 17-24.

Edwards, M, \& Ewen, A. (1996). 360 feedback: The powerful new model for employee assessment and performance improvement. New York: America Management Association.

Endang Saifuddin Anshari. (1986). Wawasan Islam: Pokok-pokok fikiran tentang Islam dan ummatnya. Jakarta: CV. Rajawali.

Endot, S. (1995). The Islamisation process in Malaysia (Unpulished doctoral dissertation). University of Bradford.

Hanafi, M., \& Sallam, B. (2006). Perspectives on Islam and management. Working Paper No.141, International Islamic University, Kuala Lumpur.

Hassan al-Banna. (1998). Konsep pembahuruan masyarakat Islam. Kuala Lumpur: Thinker Liabrary.

Hassan Langgulung. (1998). Islamic education and human resource development in Moslem countries. Kesturi, 8(1), 1-18.

Ivancevich, J. (2001). Human resource management (8th ed.). Boston: McGraw-Hill.

Jamal A. Badawi. (2002). Islamic worldview: Prime motive for development. Humanomics, 18(3), 3-25.

Joni Tamkin Borhan. (2008). Pemikiran pembangunan ekonomi berteraskan Islam [Thoughts on Islamic-based economic development]. Jurnal Usuluddin, 27, 93-107.

Junaidah Hashim. (2009). Islamic revival in human resource management practices among selected Islamic organisations in Malaysia. International Journal of Islamic and Middle Eastern Finance and Management, 2(3), 251-287.

Kazmi, A., \& Ahmad, K. (2006). Management from Islamic perspective. Instructors' resource manual. Kuala Lumpur: International Islamic University.

Khaliq Ahmad. (2004). Choice of allocation norms and perceived fairness of Malaysian corporat management. International Journal of Commerce \& Management, 14(2), 15-32.

Khursid Ahmad. (1991). Kajian dalam ekonomi Islam. Kuala Lumpur: Dewan Bahasa dan Pustaka.

King, J. E., \& Williamson, I. O. (2005). Workplace religious expression, religiosity, and job satisfaction: Clarifying a relationship. Journal of Management, Spirituality, and Religion, 2(2), 173-198. 
Latham, G., \& Wexley, K. (1994). Increasing productivity through performance appraisal (2nd ed.). Reading: Addison-Wesley Publishing.

Mansor, N., \& Ali, J. M. (1998). An exploratory study of organizational flexibility in Malaysia: A research note. International Journal of Human Resource Management, 9(3), 506-515.

Maududur Rahman, \& Muhammad Al-Buraey. (1992). An Islamic prespective of organizational controls and performance evaluation. The American Journal of Islamic Social Sciences, 9(4), 499-514.

Mohd Affandi Hassan. (1992). The tawhidic approach in management and public administration. Kuala Lumpur: National Institute of Public Administration.

Mohd Fuad Mohd Lip. (1985, April). Keikhlasan dalam setiap kehidupan. Al-Islam, hlm. 16-18.

Mohd. Nasir Omar. (2005). Akhlak dan kaunseling Islam. Kuala Lumpur: Utusan Publications and Distributors.

Mondy, R. W. (2010). Human resource management (11th ed.). New Jersey: Pearson Education.

Monir Toyeb. (1997). Islamic revival in Asia and human resourse management. Employee Relations, 19(4/5), 352-365.

Moses, J., Hollenbeck, G., \& Sorcher, M. (1993). Other people's expectations. Human Resource Management, 32, 283-297.

Muhammad Nubli Abdul Wahab. (2008). Kecemerlangan pengurusan organisasi dalam Islam. Pahang: Penerbit Universiti Malaysia.

Muhammad Syukri Salleh. (2001). Konsep dan perkaedahan pengurusan pembangunan berteraskan Islam. Pemikir, Bil. 26 (Oktober-Disember), 1- 47.

. (2002). Pembangunan berteraskan Islam. Kuala Lumpur: Utusan Publications \& Distributors.

. (2003). 7 Prinsip pembangunan berteraskan Islam. Kuala Lumpur: Zebra Editions.

Mustaq Ahmad. (2001). Etika bisnis dalam Islam. Jakarta Timur: Pustaka Al-Kautsar.

Napier, N., \& Latham, G. (1986). Outcome expectancies of people who conduct performance appraisals. Personnel Psychology, 39, 827-837.

O'Reilly, Brian. (1994). 360 feedback can change your life. Fortune, 130(8), 93-100.

Rahmad Sukor Ab. Samad \& Gooi Ai Wei. (2005). Hubungan antara iklim sekolah dengan kepuasan kerja guru sekolah menengah di Wilayah Persekutuan. Jurnal Pendidikan. Fakulti Pendidikan: Universiti Malaya. 
Rashid Muhamad Mohd Yadman Sarwan, \& Salahudin Suyurno. (2008). Pengurusan Islam: Teori dan praktis. Shah Alam: UPENA. Reave, L. (2005). Spiritual values and practices related to leadership effectiveness. Leadership Quarterly, 16(5), 255-287.

Robbins, S. P. (2005). Organizational behavior: Concepts, controversies, and applications. Englewood Cliffs, NJ: Prentice Hall.

Roberts, G. (1998). Perpectives on enduring and emerging issues in performance appraisal. Public Personnel Management, 27(3), 301-320.

Rudner, L. M. (1992). Reducing errors due to the use of judges. Practical Assessment, Research E Evaluation, 7(26), 241-271.

Sayyid Qutb. (1983). Social justice in Islam. Kuala Lumpur: The Open Press.

Sidi Gazalba. (1986). Masyarakat Islam: Pengantar sosiologi dan sosiolgrafi. Kuala Lumpur: Pustaka Antara.

Surtahman Kastin Hasan. (1993). Ekonomi Islam: Dasar dan amalan. Kuala Lumpur: Dewan Bahasa dan Pustaka.

Syed Muhammad Al-Naquib Al-Attas. (1977). Islam: Faham agama dan asas akhlak. Kuala Lumpur: Angkatan Belia Islam Malaysia. . (1978). Islam and secularism. Kuala Lumpur: Muslim Youth Movement of Malaysia. . (2005). Islamic philosophy: An introduction. ISTAC, Kuala Lumpur. Journal of Islamic Philosophy, 1,11- 43.

Tafsir Pimpinan Ar-Rahman. (n.d). Kuala Lumpur: Darulfikir.

Tayeb, M. (1997). Islamic revival in Asia and human resource management. Employee Realations, 19(4), 352-364.

Taylor, M., Tracy, B., Renard, K., Harrison, J., \& Carroll, J. (1995).

Due process in performance appraisal: A quasi-experiment in procedural justice. Administrative Science Querterly, 40(3), 495-515.

Thach, E. C. (2002). The impact of executive coaching and 360 feedback on leadership effectiveness. Leadership $\mathcal{E}$ Organization Development Journal, 23(4), 205.

Wan Liz Osman Wan Omar. (1996). Pengurusan Islam abad ke-21: Revolusi pengurusan untuk keunggulan sektor awam dan korporat. Kuala Lumpur: Utusan Publications \& Distributions.

Weaver, G., \& Agle, B. (2002). Religiosity and ethical behaviour in organizations: A symbolic interactionist perspective. Academy of Management Review, 27(1), 77-97.

Wiese, D. S., \& Buckley, M. R. (1998). The evolution of performance appraisal process. Journal of Management History, 4(3), 233-249. Wimer, S. (2002). The dark side of 360-degree feedback. Training and Development, September, 37-42. 
Yousef, D. A. (2000). Organizational commitment: A mediator of the relationships behavior with job satisfaction and performance in a non-western country. Journal of managerial psychology, 15(1), 6-24.

Yousef, D. A. (2001). Islamic work ethic-a moderator between organizational commitment and job satisfaction in a crosscultural contex. Personnel Review, 30(2), 152-169.

Yusof Ali. (1983). The holy Quran: Translation and commentary. Maryland: Amana Corporation.

Yusof Al-Qaradawi. (1984). Kebangunan Islam di antara tantangan dan ekstrimisme. Petaling Jaya: Angkatan Belia Islam.

Yusof Al-Qaradawi. (1985). Iman dan kehidupan. Shah Alam: Dewan Pustaka Fajar.

Yusof Al-Qaradawi. (2000). Ciri-ciri masyarakat Islam yang kita idamkan. (Ustaz Mohammad Zaini Yahaya Pentj.). Kuala Lumpur: Penerbitan Seribu Dinar.

Zahid Parvez., \& Pervaiz Ahmed. (2004). An Islamic perspective on the lack of social responsibility in business organization. Working Paper series no: WP005/04, Management Research Centre, Wolverhampton University Business School.

Zivnuska, S., Kacmar, K. M., Witt, L. A., Carlson, D. S., \& Bratton, V. K. (2004). Interactive effects of impression management and organizational politics on job performance. Journal of Organizational Behavior, 25, 627-640. 